\title{
The possibilities of energy storage in bulk materials
}

\author{
Pawet Ratuszny ${ }^{1, *}$ \\ ${ }^{1}$ University of Opole, Department of Process Engineering, 7-9 Dmowskiego St., 45-365 Opole, \\ Poland
}

\begin{abstract}
The increased demand for energy from renewable sources entails the development of storage systems. The purpose of these systems is to supply energy on demand during periods which may not be concurrent with the time of the most efficient production of this energy. Various systems are being developed for storing energy in various forms and over various lengths of time.This paper presents selected projects and the results of studies into thermal energy storage. The results of the present author's own research into the transport of thermal energy in granular beds are also presented. The curves of temperature distribution have been determined; they are essential for the design of the thermal storage of a granular bed. Such curves need to be determined for the given granular bed and for the conditions of its operation
\end{abstract}

\section{Introduction}

Energy storage is of key importance for the development of technologies that use renewable energy sources. Energy can be stored in various forms, using various processes. Thus, electricity can be stored directly or by means of electrical and chemical processes, while mechanical energy can be stored by means of chemical reactions and physical and chemical processes, and there is also the storage of thermal energy. Heat storage can be divided into sensible heat storage, phase changing storage (PCM) and thermochemical storage.

The research carried out, and the results presented in this paper, are of a practical and implementable nature; they make preparations for launching a project within the R\&D framework (research and development) and pertain to the storage of sensible heat for the purposes of heating buildings and domestic hot water. The aim of the research project is to use the sand-filled space between the foundation walls of buildings to create a sensible heat storage, which can be used for heating the building, as a lower source for the heat pump. Such spaces are found in each building without a basement. Sand is used for filling the space, as this material is easy to compact and relatively inexpensive. Due to the construction technology, the compacted sand deposit is created regardless, therefore the cost of heat storage there is very low, as it only requires the addition of a heat exchanger pipe, a switchgear, and a pumping station for the working medium, which may even be water. The results presented in this paper pertain to these type of projects.

\footnotetext{
* Corresponding author: ratuszny@uni.opole.pl
} 
It should be noted here that heat is not a physical form of energy and that the term "heat storage" is a common abbreviation used by many authors, but it refers to the change in the internal energy of the storage system, regardless of the medium used and the form of energy stored.

The study carried out by the author is expected to provide guidelines for the design of heat exchangers in this type of storage; the main design parameter will be the arrangement and the distance between the exchanger pipes. The appropriate arrangement of standard PEX or PE pipes, 1/2" in diameter, will ensure proper heat exchange area and optimal use of the deposit for energy storage. The design values can be determined after the heating curves have been drawn, i.e. the curves of the relationship between the temperature of the deposit and the distance from the heating element/pipe. Such curves, showing temperature distribution in a deposit, must be drawn up for the particular deposit, with its operating conditions, its structure, and its properties.

The thermal properties of materials of mineral origin are the subject of numerous studies, and their results concerning the thermal capacity of the deposit related to specific heat for various materials are widely available in the literature. However, there is no data on the distribution of the temperature in the deposit, which could be used to design heat storage facilities containing bulk materials. In his earlier works, the author presented temperature distribution in deposits for materials of different grain size and for different humidity. This paper presents the results of temperature distribution in a fluid for different degrees of compaction of the deposits.

\section{Review of the literature}

Water stores of sensible heat are commonly used in buildings. These are mainly domestic hot water storage tanks or, in less developed installations, buffer tanks which store heat from various sources, such as heat pumps, solar installations, or boilers, including wood gasifying boilers. Such tanks have a volume of $1.5-3.0 \mathrm{~m}^{3}$. The storage material is water which circulates in a closed system; this distinguishes the buffers from domestic hot water tanks, in addition to their capacity [1]. Buffer tanks allow the efficient use of solar energy by the solar power system. They also optimize the operation of heat sources. The heat pump, which is an advanced mechanical device, should operate in long switching cycles. Operation of the heat pump in frequent but short switching cycles, as in the case of gas boilers, causes faster wear and tear of the mechanical components of the pump, and thus a significant reduction in the time of trouble-free operation. In the long switching cycle excess heat occurs, for which the building has no need at that particular time. The use of a heat store - the buffer tank, allows the proper scheduling of the operaton of the pump. The same is true for a pump cooperating with a boiler gasifying wood. Such a boiler works in cycles of several hours with the heat output much higher than the demand of the building. The excess heat is stored in the buffer tank. The use of such a tank also permits the easy integration of multiple heat sources in one heating system. In a home where apart from the main heat source, e.g. gas/oil boiler, solar panels, fireplace with water jacket or biomass boiler have also been installed, the buffer tank permits easy cooperation of these devices in one installation. The tank is however a shortterm store. With a volume of $3 \mathrm{~m}^{3}$ it is not possible to store heat for heating purposes in a seasonal interval. Such attempts were made, however, the tank, which would accumulate heat in the summer, required to heat a single-family house in winter, would have to be as large as $30 \mathrm{~m}^{3}$ in volume and be very well heat-insulated. In standard homes, as a rule there is no space for its use as a heat store. Moreover, the cost of construction of such a tank would greatly reduce the profitability of such a solution.

Heat storage on a large scale, for the heating of buildings and domestic hot water, is primarily carried out in the form of sensible heat. Water accumulated in specially built 
reservoirs or in natural underground spaces is used as a storage medium. Soil or bulk solids may also be used. Intensive research is being done into the use of PCM (phase changing materials) in large storage facilities. It should be noted, however, that at this stage, the storage volume of the storage facility is reduced by about three times in relation to the storage of the sensible heat in the water storage facility [2]. Taking into account the lower costs of building a new storage facility (smaller in volume), but on the other hand the high cost of PCM materials compared to water, and their impact on the environment, this solution does not currently seem to be competitive with open heat storage systems where water or granular materials are used for heat storage

Polish soils are mostly loose or cohesive, and can make good, cost-effective energy stores depending on their thermal parameters, the degree of soil water content, and the structure of the soil. Most loose soils are in the lake regions and in the west of Poland. In the north, and in the central part of Poland, the most common soil is cohesive, in the south it is also common, however, with the exception of the mountains [3].

A knowledge of soil thermal conductivity is fundamental to understand heat transfer in soils. Experimental studies in this area have been carried out using a thermo probe method. Zhang et al. proposed a new method to measure sand thermal conductivity dryout curves using a new thermo-TDR probe. A thermo-time domain reflectormetry (TDR) probe integrates a dual-probe heat pulse device with the TDR technique for simultaneous measurements of soil water content, electrical conductivity, and thermal properties [4].

Numerous works have been published on the physico-thermal properties of granular deposits, which form geological layers. However, studies have mainly been carried out into obtaining heat from the ground using vertical and horizontal probes, or the open storage of thermal energy - BTES (Borehole Thermal Energy Storage). In such systems energy is stored in the rock or soil. The exchanger pipes are placed in holes bored in the existing ground. The quantity and depth of the boreholes depends on the amount of heat required, and on the properties of the soil. The most common diameter of the hole $150 \mathrm{~mm}$. The space between the walls of the holes and the U-tubes is filled with a cement slurry of high conductivity. In the BTES system there are from one to even several hundred heat exchangers, spaced radially from the centre of the system to its edges. The holes are most often spaced about 2$5 \mathrm{~m}$ from each other, and their depth varies from a dozen or so to $300 \mathrm{~m} \mathrm{[5].}$

For sensible heat storage, in principle a high heat capacity is required. However, all types of underground material show a volumetric thermal capacity which is about half that of water $\left(4.15 \mathrm{MJ} / \mathrm{m}^{3} \mathrm{~K}\right)$.

In order to design a thermal store of bulk materials, it is necessary to consider the nature of heat transfer in these materials. Different mechanisms will be applied for a deposit heated with a flowing liquid, and for a deposit with the pipe heat exchanger, in which the air is trapped in the voids between the grains. For such deposits where the particles are surrounded by stagnant fluid, heat transfer is assumed to occur in the vertical direction, either through the fluid in the void space, or through the solid phase. The former occurs by conduction and by radiation between adjacent voids (when the voids are assumed to contain a non-absorbing gas). The solid phase transfers heat through the contact surface of the solid particles, or via conduction through the stagnant fluid near the contact surface (when the voids are assumed to contain a non-absorbing gas).

There are two basic mechanisms of heat transfer through the fluid in the void space: by conduction, and by radiation between adjacent voids (when the voids are assumed to contain a non-absorbing gas) and heat transfer through the solid phase. In the latter case it is heat transfer through the contact surface of the solid particles, conduction through the stagnant fluid near the contact surface, radiation between surfaces of solid, and conduction through the solid phase. The mechanism and the mathematical model of heat transfer in granular deposits are described in detail in the [6], and storage of heat is shown in [7]. 
Major influences on this value are the material itself, the bulk density and the water content. In order to achieve a proper heat transport into and from the ground, a high thermal conductivity is desirable, while from the point of view of heat losses the thermal conductivity should be as low as possible. In porous underground a high groundwater can increase the heat capacity, while groundwater flow can reduce the performance of BTES significantly, because of increasing losses due to convective heat transport [8].

The Drake Landing Solar Community (DLSC) located in Canada can be an example of the implementation of an investment with BTES. The feature of DLSC is that 90 percent of space heating needs for the community's 52 single-detached homes will be met by solar thermal energy. The DLSC is also the first major implementation in North America of a technology known as seasonal solar thermal energy storage. Solar thermal energy is collected in the summer, stored underground, and then returned to the homes as heat during the winter [9].

One of the first experimental, but realized on a large scale systems of water heat store, was carried out in the 1980s in Lyckebo in Sweden. A natural underground rock reservoir with a capacity of $105000 \mathrm{~m}^{3}$ was used as the heat store. For heating water in the tank, a system of solar panels of $4300 \mathrm{~m}^{2}$ was made. The tank is integrated into the town-heating system and the heat from it is supplied to 550 homes [10].

An interesting and innovative example of heat storage executed in Poland is the system installed in the Mazowsze Psychiatry Centre "Drewnica" in Ząbki near Warsaw [11]. This is the first of its kind in Poland with the Seasonal Thermal Energy Storage (STES) seasonal heat store.It was built within the framework of the Einstein project co-financed by the European Commission. The heat is stored in the water collected in the tank with a capacity of $800 \mathrm{~m}^{3}$, diameter $14 \mathrm{~m}$, and height $8 \mathrm{~m}$, which may collect about 167,6 GJ energy before the heating season. The energy is supplied by solar panels with a total surface area of $150 \mathrm{~m}^{2}$ $[\mathrm{G}]$.

A very interesting example that uses the storage of sensible heat with the simultaneous use of phase changing is an innovative heating system available from Viessmann; the system uses an ice tank, as the lower source for the heat pump [12]. The ice storage tank is a tank with a built-in coil heat exchanger, buried in the garden and filled with water from the water mains. The roof of the house is fitted with special air-solar absorbers which collect the heat from the air and from solar radiation, and then convey it to the ice storage tank. Since the tank is buried several meters deep into the ground, it collects the heat directly from the ground as well. The pump draws sensible heat from the water in the tank, thus lowering its temperature. When the temperature in the tank falls below the freezing point, the conversion of water into ice is used to further generate heat - hence the name "ice tank" [12].

Other heat storage technologies, based on sorption processes and chemical reactions, due to their high costs are unlikely to be used to store heat for heating purposes in residential buildings. They are used in industrial technologies where the required storage time or temperature ranges are not available with sensible heat storage technologies using water or bulk materials. Similarly, the storage and transport of heat can be implemented using sorption processes [13].

No data has been found for storage facilities with sand filling, which is the subject of the research carried out by the author. It should be noted that in the sand-filled store, the heating medium is located in pipes and it does not come into direct contact with the deposit; therefore, the results of research concerning bulk deposit stores, where the heating medium flows through the deposit in the gaseous or liquid phase, are not easily transferable [14].

Due to the low unit energy storage costs, the development of sensible heat storage works seems highly justified, especially in cases where spaces (volumes) are utilised; spaces which are to be carried out for technological reasons in construction. An example of this is the construction of a heat store between the foundation walls of a building. 


\section{Methodology and materials}

The system is comprised of a measuring chamber filled with the tested granular material, the heat supply unit of a boiler with a thermostatic temperature control system for the flow of the liquid, and the temperature in various areas of the deposit. A temperature measurement was based on a measuring and control unit with a data logging function, configured for multipoint measurement and temperature monitoring. In the project, the control device was connected to 8 digital temperature sensors. TS-2 DM and 1 sensor PT-100 for monitoring the temperature of feed water as it may exceed the measuring range of sensors TS-2 DM. Figure 1 presents a system for measuring tests results.

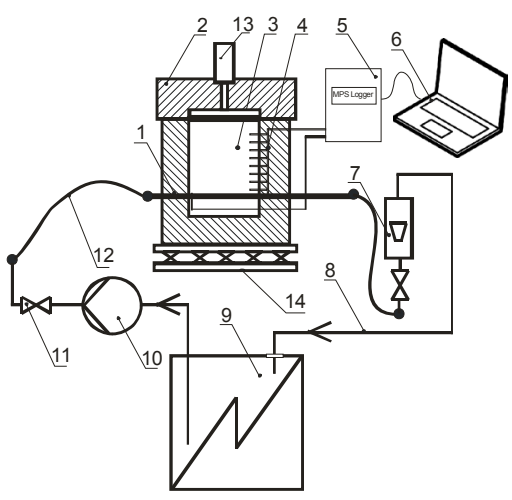

Fig. 1. The design of the laboratory workstation: $1-$ the pipe heating the deposit equipped with an inlet temperature sensor PT-100, 2 - thermal insulation of the measuring chamber, 3 - steel measuring chamber filled with loose material, 4 - temperature sensors TS$2 \mathrm{DM}$ (8 pieces), 5 - measuring unit with MPS Logger, 6 - computer working with measuring module, 7 rotameter, 8 - return of the heating water, 9 - electric thermostatic water heater, 10 - circulating pump, 11 valve, 12 - flexible cable connecting the units of the workstation, 13 - piston for compacting deposits, 14 vibrating base.

The test chamber was filled with sand, and temperature sensors were installed; a PT-100 sensor was placed on the heating water inlet and digital sensors were positioned vertically at $15 \mathrm{~mm}$ intervals. This allowed the measurement of the change in temperature of the deposit depending on the distance from the place of heat supply. The heating water temperature was $65^{\circ} \mathrm{C}$.

In order to determine the curves of bed heating depending on the degree of bed density, a special measuring chamber was made. A steel pipe was used, with a diameter of $200 \mathrm{~mm}$ and a lenght of $200 \mathrm{~mm}$. At the bottom of the chamber a heating pipe was placed. Due to the risk of damage, temperature sensors had to be placed in a fluid only after the process of mechanical compaction. For this purpose, at the side of the chamber there was made a special strip with lockable holes, through which sensors were inserted into the deposit after compaction. The chamber is positioned on a vibrating base to achieve a compaction of the deposit, as the shaking results in an even compaction of the deposit. A piston with a chydraulic cylinder was connected at the top. A preliminary series of measurements have shown that the start of the shaking device is sufficient in achieving a low compaction. A maximum density is possible after pressing the deposit, and the cylinder used allowed for a maximum pressure $0,4 \mathrm{MPa}$. The author's earlier research on the mechanical properties of granular deposits was published here $[15,16]$.

Two types of bulk material, sand, were used for the study, the properties of which are presented in Table 1. Dry materials were tested in the temperature range in which they will operate in a heat store with a sand filling, i.e. $20-65^{\circ} \mathrm{C}$, where $65^{\circ} \mathrm{C}$ is the temperature of the heating element. 
Table 1. Properties of used materials.

\begin{tabular}{|l|c|c|c|c|}
\hline & $\begin{array}{c}\text { Substance } \\
\text { (dry) }\end{array}$ & $\begin{array}{c}\text { Grains } \\
\text { dimension, } \mathrm{mm}\end{array}$ & $\begin{array}{c}\text { Volumetric heat } \\
\text { Capacity, } \mathrm{MJ} / \mathrm{m}^{3}\end{array}$ & $\begin{array}{c}\text { Density, } \\
10^{3} \mathrm{~kg} / \mathrm{m}^{3}\end{array}$ \\
\hline Material 1 & Sand (dry) & $0,5-1,2$ & 1,6 & 2,2 \\
\hline Material 2 & Sand (dry) & $1,6-2,5$ & 1,3 & 1,8 \\
\hline
\end{tabular}

The test material at $20^{\circ} \mathrm{C}$ was filled freely into the measuring chamber. The free filling methodology is based on the standard for the measurement of bulk density of granular deposits [17], according to which the measurement is to be performed precisely for the freely filled deposits. Subsequently, according to an assumed schedule, the deposits were compacted, assuming as a parameter the percentage of reduction of the deposit height. This is a standard method for determining the density of sand deposits in construction. All measurements were repeated 3 times and the averaged results were used to determine the curves of heating of the deposit for different degrees of the deposit density.

\section{Results and discussion}

The results of the measurements for the tested deposits are shown in the charts: Fig. 2 - Fig. 4. As is evident, the temperature increased in all sensors with a very similar trend, initially it grew faster, but after a while it stabilizes at a certain level for each sensor.

a)

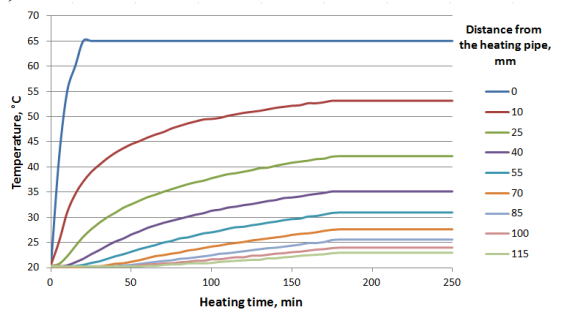

b)

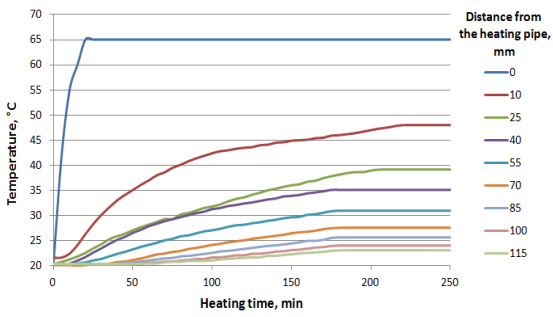

Fig. 2. The chart of changes in the temperature of the deposit depending on the distance from the heating element - for, loose-filled deposit: a) material No. 1, b) material No. 2.

a)

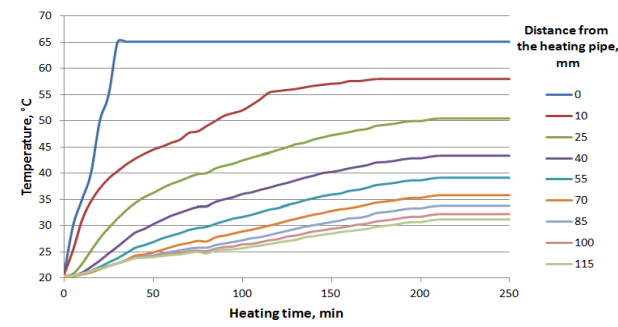

b)

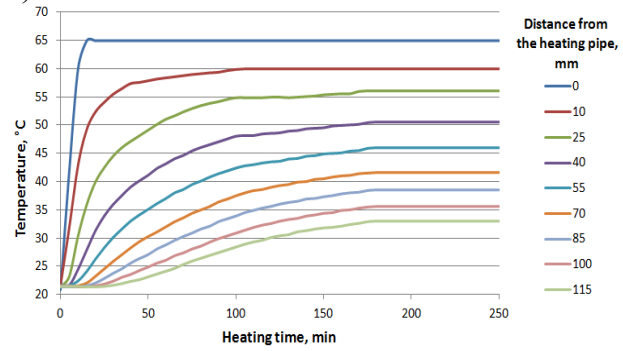

Fig. 3. The chart of changes in the temperature of the deposit depending on the distance from the heating element a) material No. 1 , deposit density $15 \%$, b) material No. 2 , deposit density $15 \%$. 
a)

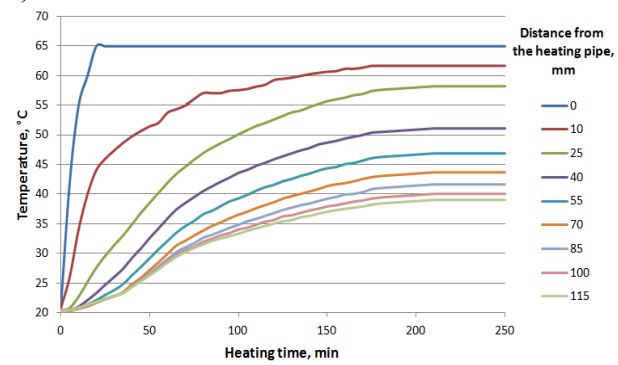

b)

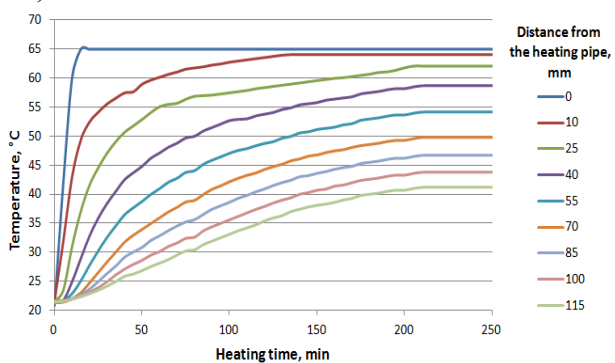

Fig. 4. The chart of changes in the temperature of the deposit depending on the distance from the heating element a) material No. 1 , deposit density $20 \%$ b) material No. 2 , deposit density $32 \%$.

Material No. 2, with much larger grains, was compacted by $32 \%$, while material No. 1 was compacted by only $20 \%$. This results directly from the size of the grains. Between the larger grains, the air spaces are larger and their removal has allowed a greater reduction in the height of the deposit. From the graphs for both materials, it is clearly visible that the temperature of the deposit after a given (specified) time period is higher for deposits with a higher density. This is due to the smaller share of air in the deposit. The air in porous materials, including insulating materials constitutes a barrier to heat transfer, therefore after it is removed, it easier to transfer heat in the deposit. Therefore the degree of density may determine the distance between the heat exchanger pipes in the sand filled heat store. The higher the density of deposits, the greater the distance between the pipes may be. From the measurements, taking into account the symmetrical way of heat transfer in the deposit, as shown in [7], in order to achieve the storage temperature of $50^{\circ} \mathrm{C}$ in the case of loose bed, the pipe's distance of $30 \mathrm{~mm}$ for material no. 1 and $45 \mathrm{~mm}$ for material no. 2 should be used. For deposits compacted to the maximum for a given material, this distance may be increased, and for the test materials it is respectively $90 \mathrm{~mm}$ and $140 \mathrm{~mm}$.

\section{Conclusions}

The presented results are in accordance with the aforementioned model of heat transfer in granular deposits. An increase in the temperature of the compacted deposit results from the heat transfer mechanism in granular deposits. After removing the air spaces, the predominant mechanism becomes heat conduction. In the case of a significant amount of air in the bed and point contact of grains, radiation and convection are the dominant mechanisms. Convection, on the other hand, is very limited here, since the air enclosed in the intergranular spaces is virtually impossible to move (as in ventilated or saturated deposits) and constitutes a barrier to heat transfer.

From the graphs presented it is also possible to read the distances of exchanger pipes, at intermediate deposit densities, for the tested sands. This is important for the fact that when building the heat store on the particular construction, it can be assumed that the deposit has been compacted to the maximum and that all air-filled spaces have been removed. However, the percentage reduction in the filling height can be evaluated and the correct distance between the heat exchanger pipes can be determined. The mapping of the heating curves, as mentioned above, must be carried out for the specific materials and working conditions of the deposit. It should be noted however that investors building houses in a specific area will be using the same resources, including the same sand deposits. There is, therefore, no need for laboratory tests for each investment separately. It is possible to develop a directory of the characteristics of the materials used for the construction of heat stores filled with sand for the given geographical area. Such a directory should contain many other properties of the available sands, which have not been the subject of the present research, such as specific heat, thermal capacity, etc., which will allow calculation of, e.g., the thermal capacity of the store. 
This requires additional studies for an individual customer. As mentioned in the introduction, the results of the research presented in this paper and in the previous works of the author are used for designing a heat store with sand filling as part of a pilot project in the area of R\&D.

\section{References}

1. A. Hauer, S. Hiebler, M. Reuss: Wärmespeicher. BINE-Fachbuch. Frauenhofer IRB Verlag, Stuttgart, ISBN 978-3-8167-8366-4 (2012)

2. M. Sterner, I. Stadler, Energiespeicher - Bedarf, Technologien, Integration. Springer Verlag, Heidelberg, DOI 10.1007/978-3-642-37380-0.8 (2014)

3. M. Tyszer, B.Tomaszewska, Ciepłownictwo, Ogrzewnictwo, Wentylacja. 47, 7, DOI 10.15199/9.2016.7.2 (2016)

4. N. Zhang, X.Yu, X. Wang, International Journal of Heat and Mass Transfer 11, p. 1054-1064 (2017)

5. A. Badache, A. Soufiane Benosman, Y. Senhadji, M. Mouli, Thermo-physical and mechanical characteristics of sand-based lightweight composite mortars with recycled high-density polyethylene (HDPE), Construction and Building Materials 163 40-52, (2018)

6. D. Kunii, J.M. Smith, A.I.Ch.E. Journal vol. 6, No.1, p. 71-78 (1960)

7. P. Ratuszny, E3S Web of Conferences 19, 01022 DOI: 10.1051/e3sconf/20171901022 (2017)

8 M. Reuss, The use of borehole thermal energy storage (BTES) systems Bavarian Center for Applied Energy Research (ZAE Bayern), Germany

9. B. Sibbitt, D. Mcclenahan, R. Djebbar, Groundbreaking Solar - Case Study, Drake Landing Solar, High Performing Buildings (2015)

10. C. Brimström, M. Larsson P. Hoist, H. Zinko, C-G. Hillström, The Lyckebo project a Swedish central solar heating plant with seasonal storage. Proceedings of the Ninth Biennial Congress of the International Solar Energy Society, Pages 61-65, Volume 1, doi.org/10.1016/B978-0-08-033177-5.50020-X, (1986)

11. Final Report Summary - Einstein (Effective integration of seasonal thermal energy storage systems in existing buildings), The pilot plant in Ząbki, Warsaw, https://cordis.europa.eu/, (2016)

12. Website and Brochure of Viessmann, www.viessmann.pl

13. Annual Report of Bavarian Center for Applied Energy Research (2012)

14. R. Lech, P. Szostak, H. Szeląg, Różne podejścia do wymiany ciepła w kalcynowanej warstwie ziarnistego wsadu wapienia - Część I: Uproszczony model wymiany ciepła, Współczynniki uproszczonego modelu, Materiały Ceramiczne (Ceramic Materials), 68, 3, 213-217 (2016)

15. S. Gajda, P. Ratuszny, Przemysł Chemiczny 9/2011, s. 1639 (2011)

16. P. Ratuszny, Przemysł Chemiczny 96/9, s.1000-1002, DOI: 10.15199/62.2017.9.XX, (2017)

17. PN-EN 1097-3:2000. 